\title{
New large subglacial lake in Princess Elizabeth Land, East Antarctica, detected by airborne geophysical observations
}

\author{
Lin $\mathrm{Li}^{1}$, Aiguo $\mathrm{Zhao}^{2,3}$, Tiantian Feng ${ }^{2,3}$, Xiangbin Cui ${ }^{1}$, $\mathrm{Lu} \mathrm{An}^{2,3}$, Ben $\mathrm{Xu}^{4}$, Shinan $\mathrm{Lang}^{4}$, Liwen \\ Jing $^{2,3}$, Tong $\mathrm{Hao}^{2,3}$, Jingxue Guo ${ }^{1}$, Bo Sun ${ }^{1}$, and Rongxing $\mathrm{Li}^{2,3 *}$ \\ $5 \quad{ }^{1}$ Polar Research Institute of China, Shanghai, China \\ ${ }^{2}$ Center for Spatial Information Science and Sustainable Development Applications, Tongji University, Shanghai, \\ China \\ ${ }^{3}$ College of Surveying and Geo-Informatics, Tongji University, Shanghai, China \\ ${ }^{4}$ Faculty of Information Technology, Beijing University of Technology, Beijing, China \\ Corresponding author: Rongxing Li (ronli_282@ hotmail.com)
}

\begin{abstract}
Knowledge of subglacial lakes is important for understanding the stability of the Antarctica Ice Sheet (AIS) and its contribution to the global sea-level change. We designed an intensified airborne campaign to collect geophysical data in Princess Elizabeth Land (PEL), East Antarctica, during the 2015-2019 CHINARE expeditions. We developed an innovative method to build a set of evidence of a newly detected subglacial lake, Lake Zhongshan. Adaptive RES data analysis allowed us to detect the lake surface and extent. We quantified the lake depth and volume via gravity modeling. Another dataset collected at Lake Vostok provided the ground truth. The results revealed that Lake Zhongshan, located at $73^{\circ} 26^{\prime} 53^{\prime \prime} \mathrm{S}, 80^{\circ} 30^{\prime} 39^{\prime \prime E}$ and $~ 3,603 \mathrm{~m}$ below surface, has an area of $328 \pm 1 \mathrm{~km}^{2}$, making it the only one in PEL and the fifth largest in Antarctica. These findings are important for understanding subglacial hydrodynamics in PEL, as well as the stability of the AIS.
\end{abstract}

\section{Introduction}

Antarctic subglacial lakes are reservoirs of water gathered beneath the Antarctic Ice Sheet (AIS) (Christianson et al., 2012; Napoleoni et al., 2020). Large subglacial lakes can affect the overlaying internal ice sheet structure, rheology of the ice body (Siegert. et al., 2000; Pattyn et al., 2018), and modulate the velocities of ice streams and outlet glaciers (Robin, 2008). Some subglacial lakes could be connected over large distances through a hierarchical hydrological chain (Siegert et al., 2016; Wingham et al., 2006). The growing evidence for a well-connected subglacial drainage system in Antarctica indicates that the subglacial hydrologic system is indispensable to understanding the mass balance of AIS and its contribution to global sea-level change (Jordan et al., 2010; Robin, 2008). Although the methodology of AIS mass balance has been widely studied (Bell et al., 2018; Rignot et al., 2019; IMBIE, 2018), the role of the subglacial hydrological system in this ice sheet mass change process is poorly understood (IPCC, 2019). Therefore, accurate detection of subglacial lakes and investigation of their hydrological connectivity are essential to learning spatial and temporal evolution of the overlaying ice sheet dynamics.

Subglacial lakes are usually recognized as a flat interface with high specularity in radargrams from radio echo sounding (RES) data (Oswald and Robin, 1973; Wright and Siegert, 2012). Until the early 1990s, RES data were the 

2, and ICESat-2, provide another important source for detecting "active" subglacial lakes since the elevation changes caused by subglacial hydrologic activities can be detected by the time-series data from satellite altimetry (Malczyk et al., 2020; Siegfried and Fricker, 2018). However, this method cannot be used to detect "definite" lakes (Rivera et al., 2015). Therefore, RES observations are still the most reliable and irreplaceable data for the detection of both active and definite subglacial lakes. Additionally, airborne gravity and seismic sounding observations have been applied to determine lake bathymetries (Studinger et al., 2004).

With great efforts in last five decades, the inventory of Antarctic subglacial lakes has been updated in a fourth edition (Wright and Siegert, 2012), and the tally of known discrete subglacial lakes has reached more than 400 (Siegert et al., 2016). However, for a long time there has been a lack of geophysical observations in the vast sector of Princess Elizabeth Land (PEL), East Antarctica, which lies between the Amery Ice Shelf and Wilhelm II Land (Cui et al., 2020b). Whether there are subglacial lakes in PEL is unknown (Fretwell et al., 2013). Under the hypothesis that ice surface expressions are closely related to subglacial features, Jamieson et al. (2016) inferred that a large subglacial lake may exist in the interior of PEL (Fig. 1b) as an elongate, extensive, and relatively featureless zone of the ice sheet surface appeared in MOA and RADARSAT imagery. This statement has not yet been verified by independent and direct geophysical observations.

We designed and carried out a geophysical data campaign during the Chinese National Antarctic Research Expedition (CHINARE) from 2015 to 2019, which aimed at filling the geophysical data gap in PEL under the auspices of the ICECAP2 program (ICECAP2, 2021), but targeted the potential subglacial lake region with intensified observations (Fig. 1a). A fixed-wing aircraft, Snow Eagle 601, collected a suite of repeated geophysical data, including RES, gravity, and magnetic data in PEL (Cui et al., 2020a). In this paper, RES and gravity data of 21 survey lines in an extended region of the potential lake are used for subglacial lake detection. The RES data in an area of seven survey lines (black line segments in Fig. 1b) show a strong water signature of basal reflectivity and prove the existence of this subglacial lake, now named Lake Zhongshan. Furthermore, we developed methods for the in-depth analysis of RES data and gravity inversion modeling which are adaptive to our data acquisition system and the local subglacial environment in PEL. We also collected another dataset from Lake Vostok using the same sensor system to provide the ground truth from a known Antarctic subglacial lake to validate our results for Lake Zhongshan. The results of this paper reveal the geometric attributes of the new lake, including location, elevation, boundary, area, volume, and bathymetry, among others. In addition, the uncertainty of the estimated and modeled parameters is analyzed. These findings are important for understanding the surface ice dynamics and subglacial hydrodynamics in PEL, as well as the stability of the Antarctic Ice Sheet. 

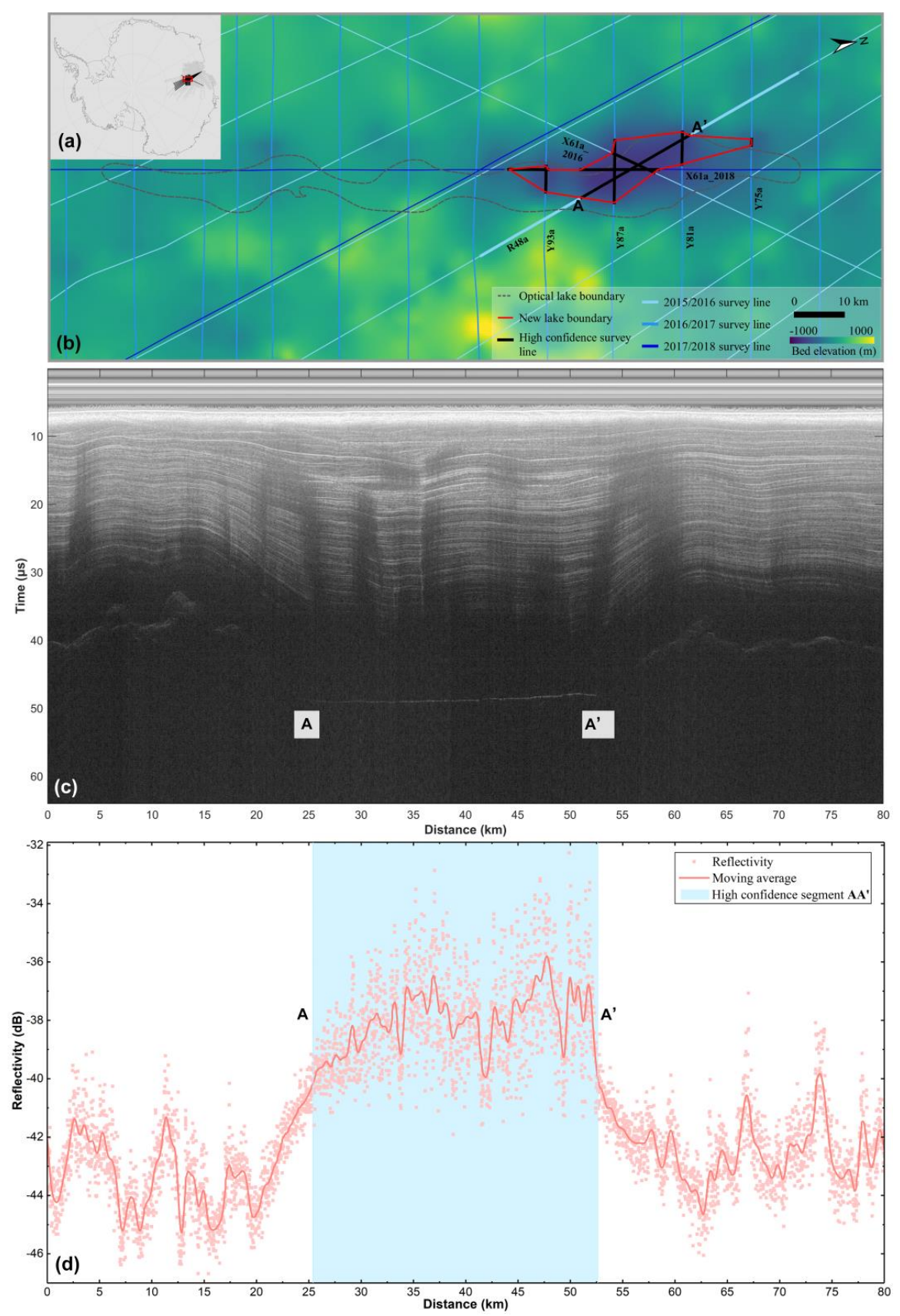

Figure 1: (a) Area of the CHINARE flight lines (black) in PEL during the 2015-2019 geophysical survey campaign. The red rectangle indicates the map extent of (b). (b) Optical lake boundary (dashed gray line) inferred from optical satellite images by Jamieson et al. (2016), new lake boundary (red line) detected in this study from RES data, and RES and gravity survey lines with high confidence segments (thick black lines) which showed strong evidence of subglacial lake in the RES data. The background is the bed elevation from BedMachine (Morlighem et al., 2020). (c) RES radargram profile containing the high confidence segment AA' of an unambiguous ice-water interface. Six other profiles of the high confidence segments are shown in Figure 5. (d) Basal reflectivity profile (red dots), moving average (red line), and subglacial lake segment AA'. 


\section{Data}

Snow Eagle 601 has successfully collected airborne RES data along flight lines of more than 175,000 km during the PEL geophysical data campaign from 2015 to 2019 (Cui et al., 2020a). The penetration capability of these RES instruments has been confirmed by the detection of Lake Vostok with an ice thickness of $\sim 4,200 \mathrm{~m}$ (Cui et al., 2018). Guided by the predicted lake boundary (dashed gray line in Fig. 1b) of Jamieson et al. (2016), we selected all survey lines covering its neighborhood from three datasets collected from 2015 to 2018 . The first dataset collected during the 2015/2016 season has five survey lines that run across the predicted lake boundary and form a pattern radiating from the airfield near the Zhongshan Station to the interior of PEL (Fig. 1b). The second dataset of 13 survey lines collected during the following season of 2016/2017 were flown approximately in the east-west direction at a higher resolution in the lake area. The third dataset intensified the survey during the season of 2017/2018 by the addition of two survey lines. The average flight altitude was $\sim 600 \mathrm{~m}$ above the ice surface to guarantee sufficient penetration capability and avoid signal saturation for a high gain radar channel (Cui et al., 2020a). The radar dataset was sampled every $\sim 17 \mathrm{~m}$ along-track, and the depth resolution is $\sim 5.6 \mathrm{~m}$ in ice. Raw data collected from the survey flights were converted into readable datasets and georeferenced by using onboard near real-time GNSS positions through the Environment for Linked Streams Acquisition (ELSA) system developed by the University of Texas Institute for Geophysics (UTIG) (Ng et al., 2020). The data quality was carefully controlled through both high and low gain channels.

The gravity data were acquired on the same survey flights as the RES data by a GT-2A airborne gravimeter (Cui et al., 2018). This three-axis stable scalar gravimeter can perform high-precision gravity data collection under turbulent air currents and varying flying heights. Four JAVAD Delta dual-frequency and carrier phase GNSS receivers were installed at four different positions on the aircraft (two wings, front and center of the fuselage), providing a positional accuracy of $25 \mathrm{~cm}$ under normal circumstances (Smoller et al., 2015). In addition, the connection between the GNSS antennas and the GT-2A system was boresight calibrated. Thus, the gravity data (and further the RES data) were georeferenced by the GNSS system in both time and space. The gravity data sampling frequency is $2 \mathrm{~Hz}$. Free-air gravity anomalies were filtered with a $200 \mathrm{~s}$ full wavelength filter, resulting in a $\sim 8.3 \mathrm{~km}$ half-wavelength resolution for the flight speed of $\sim 300 \mathrm{~km} / \mathrm{h}(\sim 83 \mathrm{~m} / \mathrm{s})$. A Kalman filter was applied in real-time to eliminate the effect of additional horizontal acceleration during flight.

\section{Methods}

\section{$105 \quad 3.1$ Detection of subglacial lake surface using basal radar reflectivity}

Detection of subglacial lakes is mainly realized by analyzing the radar reflectivity from the bed of the ice caps in RES radargram profiles (Fig. 1c) and further identifying the ice-water interface as the lake surface. To distinguish potential lakes from their surroundings, we rearrange the radar equation (Bogorodskiy et al., 1985; Peters et al., 2007) for estimating reflection $\mathrm{R}$ as follows: 
where $P_{t}$ and $P_{r}$ denote the transmitted and received power, respectively, $G_{a n t}$ is the antenna gain, $\lambda$ is the wavelength of the carrier frequency, $T_{a i}$ is the transmission coefficient at the air-ice interface, $R_{i b}$ is the reflection loss of the icebedrock interface, $G$ is the system gain, $H$ is the ice thickness, $h$ is the height of the aircraft above ground, and $L_{A}$ is the ice attenuation loss. The received power $P_{r}$ is obtained by integrating power across $\pm 800 \mathrm{~ns}$ of the picked bed position (Humbert et al., 2018). The ice attenuation loss $L_{A}$ is integrated over the travel path between the surface $h_{s}$ and the base $\mathrm{h}_{\mathrm{b}}$ (Matsuoka et al., 2010):

$\left[\mathrm{L}_{\mathrm{A}}\right]_{\mathrm{dB}}=\left[\int_{\mathrm{h}_{\mathrm{b}}}^{\mathrm{h}_{\mathrm{s}}} \mathrm{A}(\mathrm{z}) \mathrm{dz}\right]_{\mathrm{dB}}$

where the $\mathrm{A}(\mathrm{z})$ denotes the local attenuation rate per unit path length in the vertical $(\mathrm{z})$ direction. We quantify the A(z) following previous studies (e.g., Humbert et al., 2018; MacGregor et al., 2007; Matsuoka et al., 2010, 2012;

Zirizzotti et al., 2010):

$[A(z)]_{d B}=8.686 \sqrt{\frac{\mu_{0}}{\varepsilon_{0} \varepsilon^{\prime}}} \frac{\sigma(z)}{2}=914.63 \sigma(z)$

where $\varepsilon_{0}=8.8541878176 \times 10^{-12} \mathrm{~F} / \mathrm{m}^{-1}$ and $\mu_{0}=1.25663706 \times 10^{-6} \mathrm{~N} / \mathrm{A}^{2}$ are the free space dielectric permittivity and magnetic permeability, respectively. The conductivity $\sigma(z)$ is calculated by the Arrhenius model as follows:

$\sigma(z)=\sigma_{0} \exp \left[\frac{E}{k} \exp \left(\frac{1}{T_{r}}-\frac{1}{T(z)}\right)\right]$

where $E$ is the activation energy, $k$ is the Boltzmann constant, and $\sigma_{0}$ is the reference conductivity for ice, which can be affected by the impurities. In this study, we set $\sigma_{0}$ at $T_{r}=251 \mathrm{~K}$ (Matsuoka et al., 2012). We finally visually evaluate variations of the reflectivity that represent the returned power from the bottom of the ice-water and ice-rock interfaces. Any region with an abrupt increase in bed return power that exceeds a threshold ranging from $2.0 \mathrm{~dB}$ (Carter et al., 2007) to $7.7 \mathrm{~dB}$ (Zirizzotti et al., 2010) may be a safe indicator of a subglacial water body.

\subsection{Lake depth estimation by gravity inversion}

We use the GT-2A gravity data in the same map extent as the RES dataset to estimate the lake depth through gravity inversion. The Parker inversion method (Parker, 1972) implemented in the Geosoft GM-SYS 3D system is used to iteratively approach the lake bottom by minimizing the misfit between the calculated and observed gravity values. In principle, the variation in a gravity field can be observed and presented as gravity anomaly $\Delta g$ that can be further modeled from the density contrast across the interface between two layers $\rho$, depth to the interface $h(x)$, among other parameters. Its Fourier transform is expressed as

$F(\Delta g)=-2 \pi G \rho e^{-k z_{0}} \sum_{n=1}^{\infty} \frac{k^{n-1}}{n !} F\left[h^{n}(x)\right]$

where $G$ is the universal gravitational constant, $k$ is the wave number, $h(x)$ is positive downward, and $\mathrm{z}_{0}$ is the mean depth of the horizontal interface. The model domain is represented as three horizontal layers: a) a solid ice layer with a density of $0.917 \mathrm{~g} / \mathrm{cm}^{3}, \mathrm{~b}$ ) a lake water layer with a density of $1.028 \mathrm{~g} / \mathrm{cm}^{3}$, and c) a rock layer with a density of 2.67 $\mathrm{g} / \mathrm{cm}^{3}$. In a prior study, we showed that this three-layer model provided superior performance compared to a four- 

A forward gravity model is calculated using BedMachine Antarctica data (Morlighem et al., 2020) as the initial bed solution (Fig. 3c). We then calculate the direct current (DC) shift or difference between the modeled and observed gravity at locations where the ice thickness is known from the RES data (Fig. 1b). At each location along the survey line, the DC shift exhibits the vertical spatial variation that reflects the varying water layer used to approach an optimal lake depth. We then produce a regular grid of the DC shift using a minimum curvature interpolation algorithm (Smith and Wesse, 1990, Fig. 4b). We then correct the observed gravity with the interpolated DC shift and use it as input to the inversion model to account for the original bias. Since we fill observational gaps between the survey lines with the regionally corrected model data (Fig. 4c), the impact of the data gaps on the inversion process, especially at the edges of the survey region, is minimized. We allow an $8000 \mathrm{~m}$ wide horizontal transition to enable a smooth transition from the model to the observations so that all observations are preserved. The grid spacing is chosen as $1000 \mathrm{~m}$. The lake depths are finally estimated by the gravity inversion method, which minimizes the misfit between the observed and modeled gravity. We also generate an error map for the lake bathymetry product (Fig. 4a).

\section{Lake Zhongshan - the newly detected subglacial lake in PEL}

Here we present the geophysical evidence of the newly detected subglacial lake, now named Lake Zhongshan, in PEL, East Antarctica.

\subsection{Localization and attributes of Lake Zhongshan derived from RES observations}

Initially, an extensive search for basal reflectivity anomalies based on Equations (1-4) was performed using all RES data collected along the survey lines (Fig. 1a), especially along those around the optical lake boundary (Fig. 1b). Finding of the vertical zone of the bedrock layer and determination of the ice-water interfaces were mainly carried out by visual interpretation of the features presented in the RES radargram profiles (Fig. 1c). Any relatively long and bright linear features, compared to that of the surrounding bedrock, are considered candidates for the ice-water interface. We then confirm a high confidence segment of a subglacial lake if its maximum reflectivity increase exceeds $7 \mathrm{~dB}$ and the average reflectivity increase is over $3 \mathrm{~dB}$. For example, survey line segment AA' in Fig. 1b showed the longest bright stretch of $80 \mathrm{~km}$ in this region (Fig. 1c), with an average reflectivity increase of $4.8 \mathrm{~dB}$ and the maximum increase over $9.5 \mathrm{~dB}$ in the middle section (Fig. 1d). This is thus considered a high confidence segment (black line in Fig. 1b). Subsequently, six other high confidence segments were detected in the same way (Figs. 2 and 1b). The overall

average reflectivity increase for all seven segments is $3.6 \pm 1.0 \mathrm{~dB}$ and their maximum reflectivity increases range from 7.2 to $10.2 \mathrm{~dB}$, indicating a high level of confidence that the RES data along these segments provide the areal signature of a subglacial lake from a radargram point of view. 

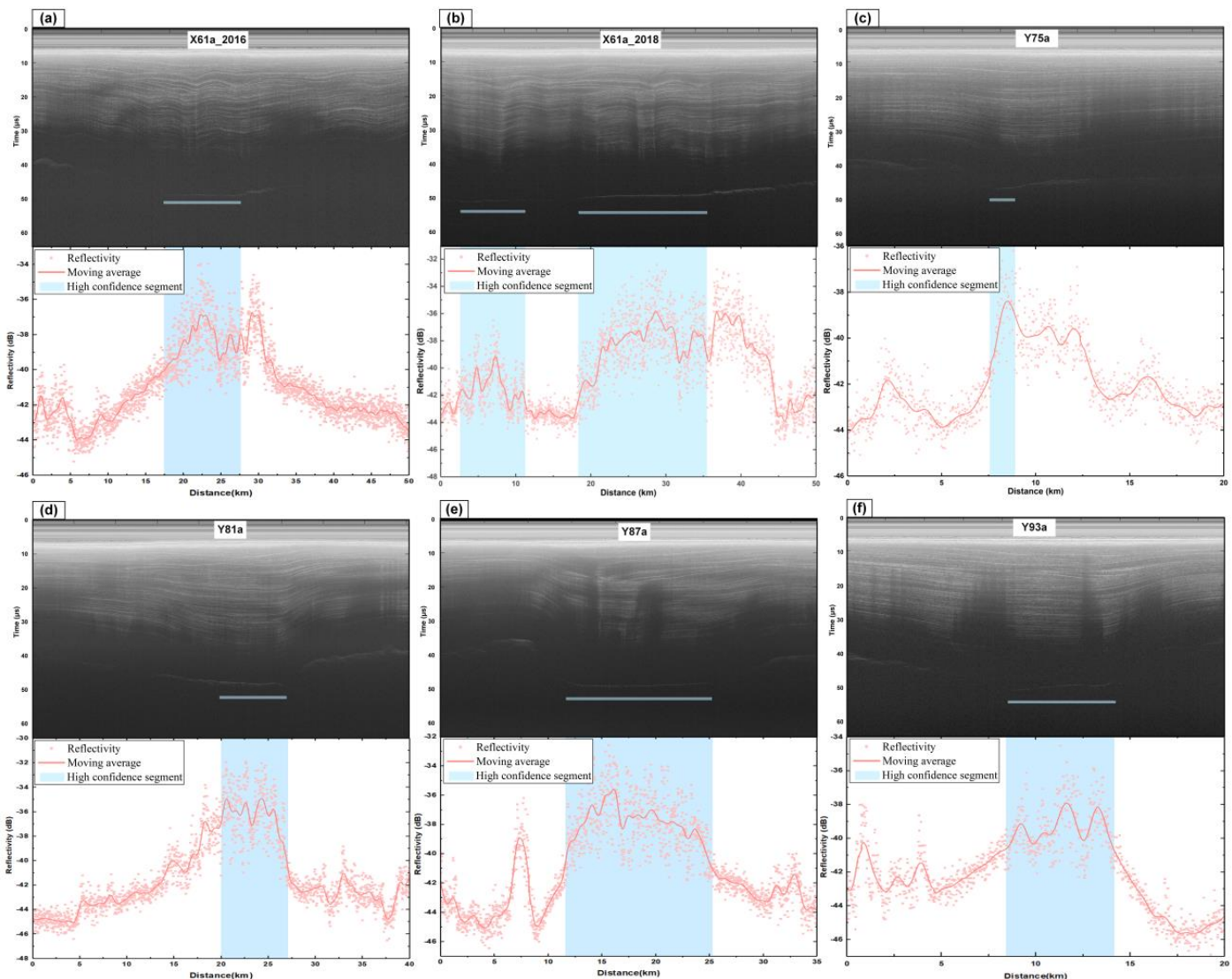

Figure 2: (a)-(f) Radargrams (upper) and basal reflectivity (lower) of high confidence segments along 6 survey lines as identified and shown in Figure 1b. The ice-water interface is above light blue lines in radargrams, and their corresponding signatures are shown in light blue boxes in the reflectivity profiles.

On the other hand, the combined RES survey lines of all three austral seasons in the region have an average spacing of $14 \mathrm{~km}$ between the lines. With three intensified survey lines, the area of the high confidence segments has a densified average spacing of $7.6 \mathrm{~km}$. Furthermore, we have a high radar sampling spacing of $\sim 17 \mathrm{~m}$ along-track. Therefore, the seven high confidence segments are combined to form a "continuous" lake area enclosed by a boundary (red line in Fig. 1b) formed by linking the end points of the high confidence segments. Consequently, the lake's dimensions are determined to be $45,200 \pm 28 \mathrm{~m}$ in length and $10,900 \pm 28 \mathrm{~m}$ in width. The area within the lake boundary is $328 \pm 1.5 \mathrm{~km}^{2}$. Thus, Lake Zhongshan is the fifth largest in Antarctica. We determined the center of the lake boundary as the geographic location of the lake $\left(73^{\circ} 26^{\prime} 53^{\prime \prime} \mathrm{S}, 80^{\circ} 30^{\prime} 39^{\prime \prime} \mathrm{E}\right)$ with an uncertainty of under $1 \mathrm{~m}$. In addition, the bed elevation data show a basin topography in the detected lake area (Fig. 1b). Based on the ice cap surface model of REMA (Howat et al., 2019) and the RES data, we estimated that the lake surface lies $\sim 700 \mathrm{~m}$ below sea level and the ice above the lake is $\sim 3603$ m thick. 


\subsection{Depth of Lake Zhongshan modeled from gravity data}

The observed gravity anomalies along the survey lines within the area vary from - $35 \mathrm{mGal}$ in the RES-derived lake area to $55 \mathrm{mGal}$ in the surroundings (Fig. 3a). The modeling results from the gravity data using Equation (5) present a subglacial lake whose boundary shape generally matches that of the RES lake boundary (Fig. 3b). The lake is asymmetric in the north-south direction and contains two non-flat lake basins with a water depth of 200-250 m. The northern basin is $50 \mathrm{~m}$ deeper and approximately double the area of the southern basin. The ridge that connects the two basins is as shallow as $\sim 150 \mathrm{~m}$. We estimated a lake volume of $54 \mathrm{~km}^{3}$. Furthermore, the bed topography presented by the BedMachine Antarctica (Morlighem et al., 2020) was used as an initial interface between the ice and bedrock in the larger surrounding region of the lake for the gravity modeling process (Fig. 3c). Within the lake area, the gravityinferred bed (Fig. 3d) is on average $\sim 200 \mathrm{~m}$ deeper than the initial bed The surrounding area outside of the optical lake boundary is not changed during the inversion process. This indicates that the collected airborne gravity data and the gravity model fit well for the overall region, while the observed gravity anomalies within the lake area provide evidence of the existence of a water body.

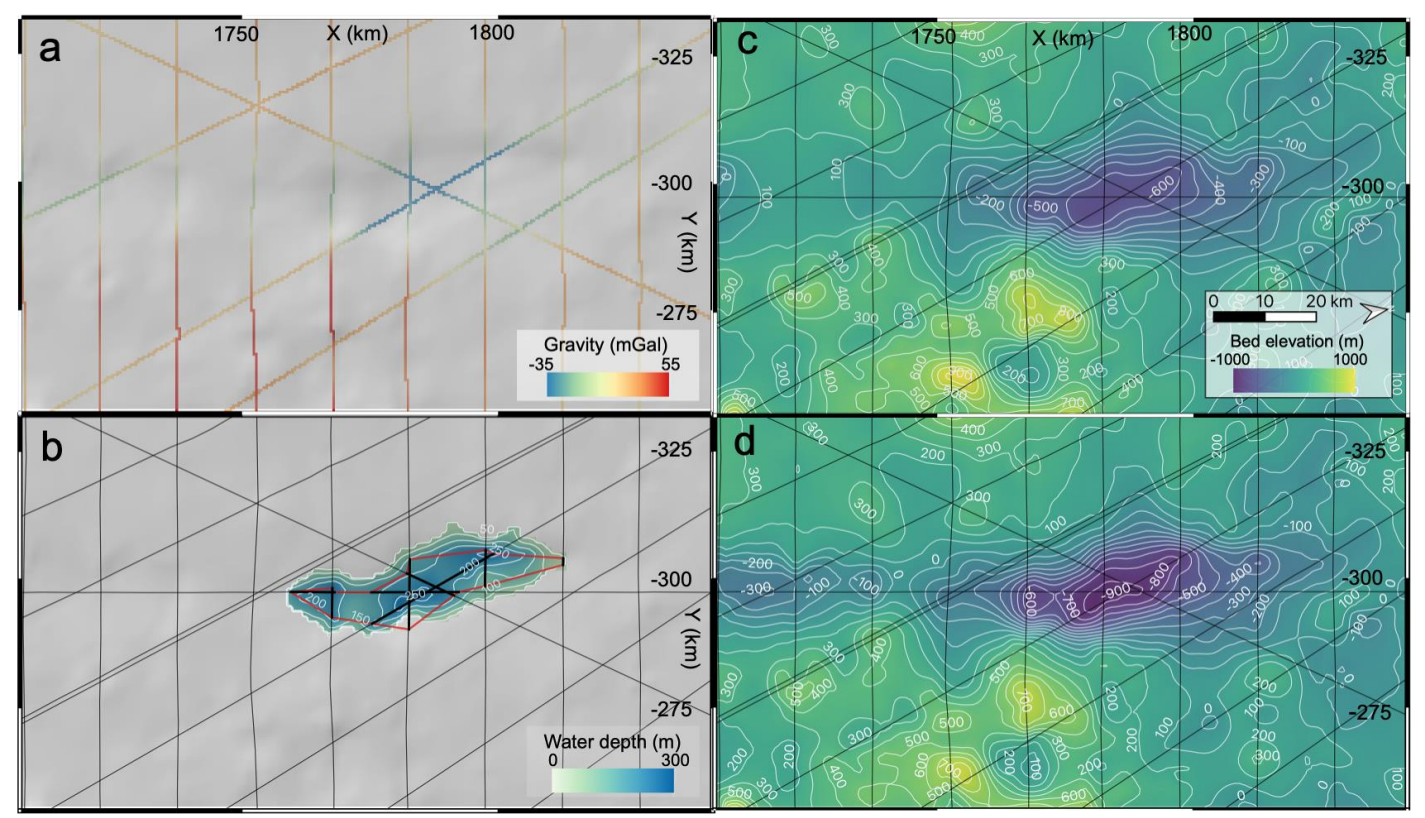

Figure 3: (a) Observed airborne gravity anomalies, color coded from blue (-35 mGal) to red (55 mGal), along the survey lines in the same area as Figure 1b. (b) Water depth and boundary of the subglacial lake modeled from the gravity data, with the depth contoured every $50 \mathrm{~m}$ and color coded from light green $(0 \mathrm{~m})$ to blue $(300 \mathrm{~m})$. (c) Bed elevations from BedMachine Antarctica (Morlighem et al., 2020) are used as the initial bed surface in the model. (d) Bed topography is inferred from gravity modeling, indicating a deeper lake bed. The color coding is same as that in (c). The background in (a) and (b) is from the Landsat image mosaic of Antarctica (LIMA) (Bindschadler et al., 2008). The black lines in (b-d) are survey lines.

We use the gravity misfit estimated as the difference between the modeled gravity and the observed gravity to quantify the uncertainty of the inversion (Fig. 4a). To translate the gravity misfit into an error in bed elevation, we performed a numerical experiment in which we calculated the differences between the gravity field in the region and 

of water increase. The median and standard deviation of the misfit are $0.48 \pm 2.8 \mathrm{mGal}$, which corresponds to $50-70 \mathrm{~m}$ in bed elevation and is defined as the uncertainty of the inferred lake bed.

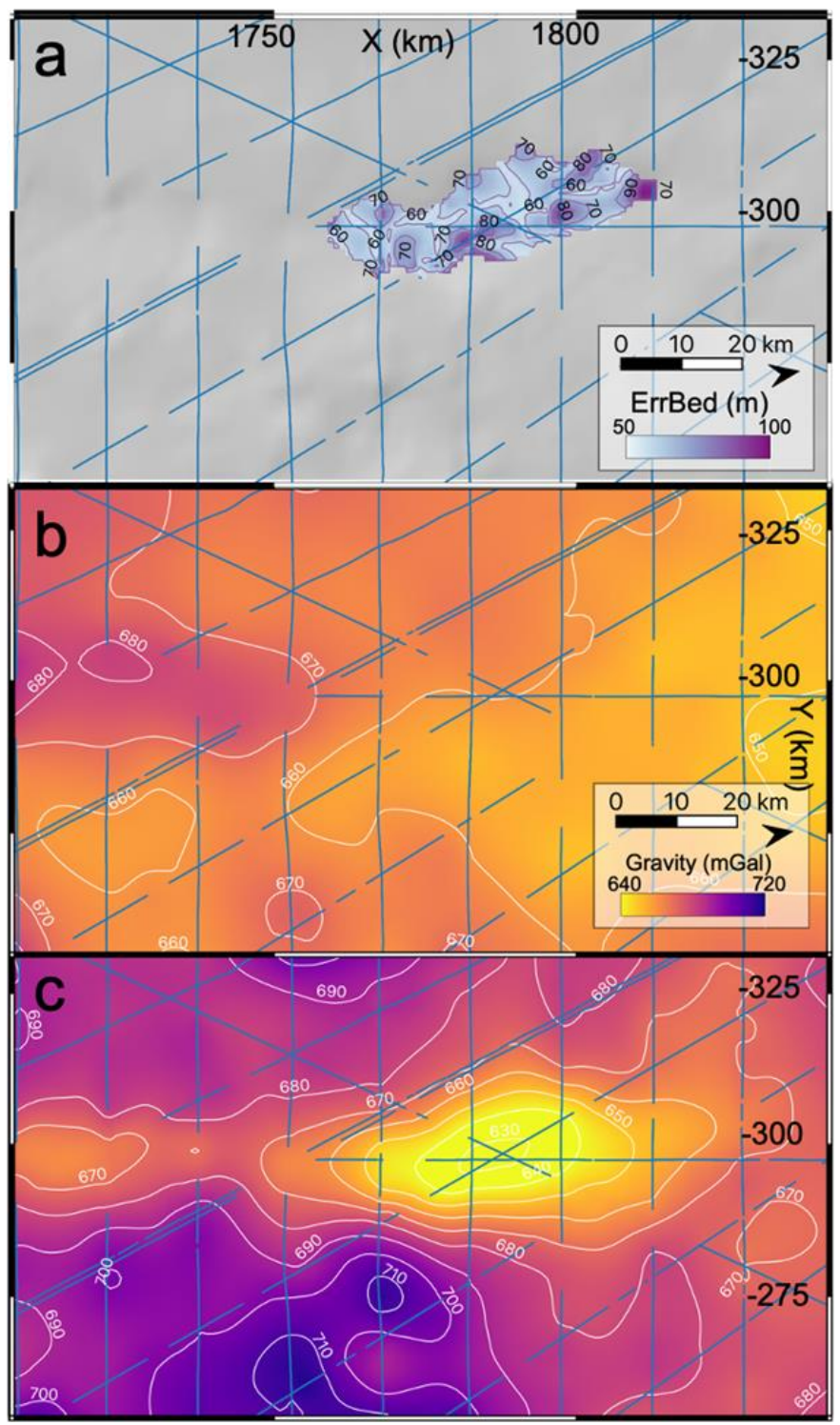

Figure 4: Uncertainty and intermediate results of the inferred lake depth: (a) Uncertainty of the inferred lake depth (Figure $2 \mathrm{~b}$ ), defined as the gravity inversion misfit converted from $\mathrm{mGal}$ to meter and color-coded from pale blue (50 $\mathrm{m}$ ) to purple $(\mathbf{1 0 0} \mathrm{m})$. Ice thickness from RES data along survey lines (blue lines) was used as constraints. (b) DC shift over the entire area Interpolated using a minimum curvature algorithm. (c) Input gravity to the inversion model after the DC shift is added 


\section{Discussion and conclusions}

Along the survey lines of X61a_2016, X61a_2018, Y75a and Y81a (Fig. 1b), there are connecting areas among the lake segments where the reflectivity values are as high as on the ice-water interface (Figs. 2a-2d). However, the corresponding brightness features in the radargrams are of high roughness and are not as flat. They appear to represent shallow lake boundary areas of a wet sediment layer. In fact these areas are coincident with the extended shallow areas of the gravity-inferred lake outside of the RES lake boundary (red line) in Figure 2b. We used a 3D gravity modeling method that does not include the sediment layer because of its resulting uncertainty. In future research, we will expand our gravity modeling with more components to determine the sediment layer of the lake.

We recommend using the RES lake boundary (red line in Fig. 1b) as the boundary of Lake Zhongshan, inside of which the high confidence segments were directly determined from the high RES reflectivity of the ice-water interface. During the campaign two GNSS base stations were usually installed on the runway area to facilitate differential GNSS data processing of the airborne GNSS positioning data. The aircraft GNSS receivers started recording at least $30 \mathrm{~min}$ before each flight to ensure pre-flight reference measurements (Cui et al., 2018; 2020b). Thus, the survey line positioning error is $25 \mathrm{~cm}$, which was given for flight lines surveyed using differential GNSS positioning (Cui et al., 2018). Furthermore, the RES sampling spacing is $\sim 17 \mathrm{~m}$. Combining these two error sources, we estimate that the uncertainty of the lake boundary uncertainty is $\sim 17 \mathrm{~m}$. The vertical uncertainty of the lake attributes are related to the accuracy of the airborne GNSS positioning and the RES and gravity observations. An analysis of the ice thicknesses at the crossovers from different RES survey lines in PEL showed a vertical accuracy of $\sim 10$ to $40 \mathrm{~m}$ (Cui et al., 2020b), which can be treated as the accuracy of the derived lake surface. Furthermore, the inferred lake depth has an accuracy of $50-70 \mathrm{~m}$.

The lack of geophysical observations in PEL has resulted in uncertainties in modeling the subglacial lake and channel system in this region (Mackie et al., 2020). The results of this study and the updated version of BedMachine (Morlighem et al., 2020) will provide important knowledge and data for the study of the mechanism of subglacial hydrodynamics that controls the water discharge from the interior of PEL to the Amery Ice Shelf and the Southern Ocean (Bell, 2008; Jamieson et al., 2016; Pattyn et al., 2016).

250 The same ELSA onboard data acquisition system of Snow Eagle 601 was tested at Lake Vostok on January 24, 2016 and collected data along a $\sim 297 \mathrm{~km}$ U-shaped surveying line in the western part of the lake (Fig. 5a). The RES profile shows a clear distinction between brightness features in radargram from bedrock and the $\sim 68 \mathrm{~km}$ long lake segment BB' (Fig. 5b). For consistency with the computation in Lake Zhongshan, the sediment area of higher reflectivity (left of point B in Fig. 5b) is excluded from the high confidence segment BB'. In accordance, we detected a maximum reflectivity increase of $23.8 \mathrm{~dB}$ and an average reflectivity increase of $8.6 \mathrm{~dB}$ from the bedrock to the lake surface (Fig. 5c). Although the largest reflectivity increase measurements of all seven segments in Lake Zhongshan, $10.2 \mathrm{~dB}$ (maximum) and $5.1 \mathrm{~dB}$ (average) (Table 1), are lower than those of the known subglacial lake environment in Lake Vostok, we notice that the reflectivity of the bedrock itself in the Lake Zhongshan area is also significantly 

layers in the Lake Zhongshan region, as indicated in Figure 7 in Matsuoka et al. (2012). Therefore, in such a region with highly attenuated RES signals through ice layers (Hills et al., 2020), the reflectivity contrast between water and bedrock may be hampered. Thus, the calculated average reflectivity increases in Lake Zhongshan, $5.1 \mathrm{~dB}$ (strongest segment) and $3.6 \mathrm{~dB}$ (average of all seven segments), are believed to be a safe indicator.
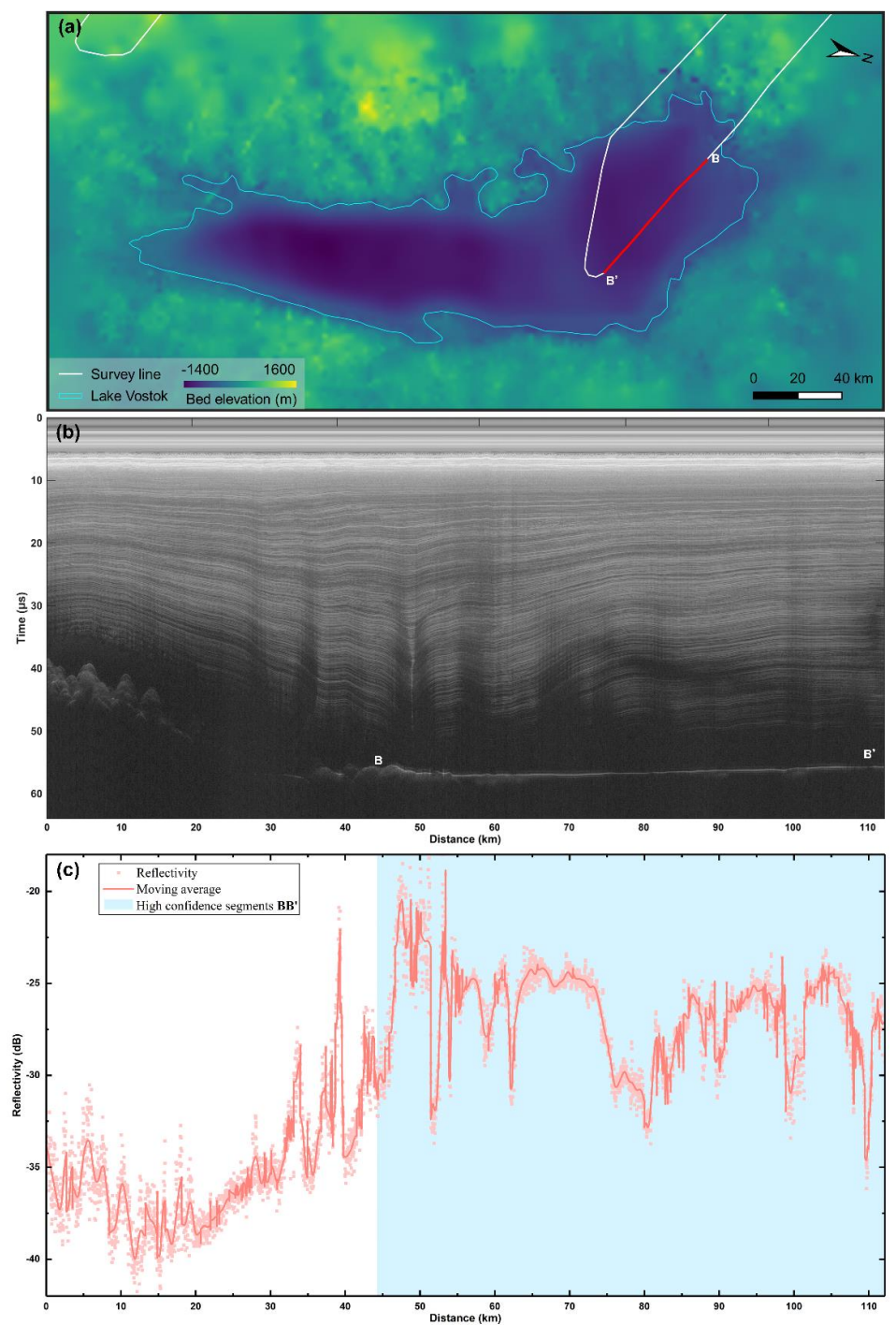

Figure 5: Ground truth in Lake Vostok: (a) RES survey line and location of high confidence segment BB', (b) radargram containing BB', and (c) reflectivity of the profile in (b). The background in (a) is the bed elevation from BedMachine (Morlighem et al., 2020). 
Table 1. Computation of average and maximum reflectivity increases from bedrock to lake surface for all seven high confidence segments in Lake Zhongshan, East Antarctica

\begin{tabular}{|c|c|c|c|c|c|c|}
\hline \multirow{2}{*}{ Survey line } & \multicolumn{3}{|c|}{ Average reflectivity $(\mathrm{dB})$} & \multicolumn{3}{|c|}{ Max and Min reflectivity $(\mathrm{dB})$} \\
\hline & Lake & Bedrock & Increase & Max (Lake) & Min (Bedrock) & Increase \\
\hline Y81a & -38.5 & -42.5 & 4.0 & -34.9 & -45.1 & 10.2 \\
\hline X61a2016 & -38.4 & -41.6 & 3.2 & -36.8 & -44.0 & 7.2 \\
\hline Y75a & -39.2 & -42.2 & 3.0 & -36.2 & -45.1 & 8.9 \\
\hline Y93a & -39.4 & -43.0 & 3.6 & -37.9 & -45.6 & 7.7 \\
\hline Y87a & -37.9 & -42.9 & 5.1 & -35.6 & -45.1 & 9.5 \\
\hline X61a2018 & -39.3 & -41.1 & 1.8 & -35.9 & -43.9 & 8.1 \\
\hline R48a & -38.0 & -42.8 & 4.8 & -35.8 & -45.3 & 9.5 \\
\hline Average & -38.7 & -42.3 & 3.6 & -36.2 & -44.9 & 8.7 \\
\hline Std. & 0.6 & 0.7 & 1.0 & 0.9 & 0.6 & 1.0 \\
\hline
\end{tabular}

In summary, we developed an innovative and systemic method to build a set of evidence of the newly detected subglacial lake, Lake Zhongshan. We designed a targeted and intensified data acquisition strategy to collect both RES and gravity data in the PEL region using the ELSA system onboard the fixed wing aircraft, Snow Eagle 601, during the CHINARE expeditions from 2015 to 2019. Adaptive RES data analysis allowed us to detect the ice-water interface and the lake extent. We quantified the lake depth, volume, and other characteristics by gravity inversion modeling. We report that Lake Zhongshan is located at $73^{\circ} 26^{\prime} 53^{\prime \prime} \mathrm{S}, 80^{\circ} 30^{\prime} 39^{\prime \prime} \mathrm{E}$ and is $\sim 3603 \mathrm{~m}$ below the ice surface of PEL, East Antarctica. Its dimensions are $45,200 \pm 28 \mathrm{~m}$ in length and $10,900 \pm 28 \mathrm{~m}$ in width. The lake area is $328 \pm 1.5 \mathrm{~km}^{2}$ and thus, it is the only subglacial lake detected in PEL and by area it is the fifth largest in Antarctica. The deepest part of the lake bed is $250 \pm 70 \mathrm{~m}$ from the lake surface and $\sim 900 \mathrm{~m}$ below the sea level. The water volume of the two-basin lake is $\sim 54 \mathrm{~km}^{3}$. These findings are important to understand surface ice dynamics and subglacial hydrodynamics in PEL, as well as the stability of the Antarctic Ice Sheet. The results can also provide supporting data for potential drilling into the lake. In the future, the evolution of this subglacial lake will be explored with additional remote sensing data, continued airborne data collection, and eventual in situ or core observations.

Data availability. The RES data are currently included in appendix as graphyics. Readers can access the data at NSIDC (https://nsidc.org/data) when the paper is accepted.

Author contributions. RL and BS led the study, LL, RL, AZ, TF, LA, XC and TH carried out data analysis and editing, BS, XC and JG collected data, XC, BX, SL and LJ processed RES data, LA and LL performed gravity modeling, all authors were involved in writing and presentation.

Competing interests. The authors declare that they have no conflict of interest.

Acknowledgements. Logistic and technical support provided by the CHINARE program, the Polar Research Institute of China, and the Snow Eagle 601 operation team is appreciated. 
Financial support. This work was supported by the National Science Foundation of China (No. 41730102).

\section{References}

An, L., Rignot. E., Mouginot, J., and Millan, R.: A Century of Stability of Avannarleq and Kujalleq Glaciers, West Greenland, Explained Using High-Resolution Airborne Gravity and Other Data, Geophys. Res. Lett., 45(7), 31563163, https://doi.org/10.1002/2018GL077204, 2018.

Bell, R. E., Banwell, A. F., Trusel, L. D., and Kingslake, J.: Antarctic surface hydrology and impacts on ice-sheet mass balance, Nat. Clim. Change., 8(12), 1044-1052, https://doi.org/10.1038/s41558-018-0326-3, 2018.

Bell, R. E. The role of subglacial water in ice-sheet mass balance, Nat. Geosci., 1(5), 297-304, https://doi.org/10.1038/ngeo186, 2008

Bogorodskiy, V. V., Bentley, C. R., and Gudmandseon, P. E.: Radioglaciology (Vol. 1), Springer Science \& Business Media., 1985.

Carter, S. P., Blankenship, D. D., Peters, M. E., Young, D. A., Holt, J. W., and Morse, D. L.: Radar-based subglacial lake classification in Antarctica, Geochem. Geophys. Geosyst., 8(3), Q03016,

https://doi.org/10.1029/2006GC001408, 2007.

Christianson, K., Jacobel, R. W., Horgan, H. J., Anandakrishnan, S., and Alley, R. B.: Subglacial Lake Whillans Icepenetrating radar and GPS observations of a shallow active reservoir beneath a West Antarctic ice stream, Earth and Planetary Science Letters., 331-332, 237-245, https://doi.org/10.1016/j.eps1.2012.03.013, 2012.

Cui, X., Greenbaum, J. S., Lang, S., Zhao, X., Li, L., Guo, J., and Sun, B.: The Scientific Operations of Snow Eagle 601 in Antarctica in the Past Five Austral Seasons, Remote Sensing., 12(18), 2994, https://doi.org/10.3390/rs12182994, 2020a.

320 Cui, X., Greenbaum, J. S., Beem, L. H., Guo, J., Ng, G., Li, L., Blankenship, D., and Sun, B.: The First Fixed-wing Aircraft for Chinese Antarctic Expeditions: Airframe, modifications, Scientific Instrumentation and Applications, Journal of Environmental and Engineering Geophysics., 23(1), 1-13. https://doi.org/10.2113/JEEG23.1.1, 2018.

Cui, X., Jeofry, H., Greenbaum, J. S., Guo, J., Li, L., Lindzey, L. E., Habbal, F. A., Wei, W., Young, D. A., Ross, N., Morlighem, M., Jong, L. M., Roberts, J. L., Blankenship, D. D., Bo, S., and Siegert, M. J.: Bed topography of Princess Elizabeth Land in East Antarctica, Earth Syst. Sci. Data., 12(4), 2765-2774, https://doi.org/10.5194/essd-12-27652020, 2020b.

Fretwell, P., Pritchard, H. D., Vaughan, D. G., Bamber, J. L., Barrand, N. E., Bell, R., Bianchi, C., Bingham, R. G., Blankenship, D. D., Casassa, G., Catania, G., Callens, D., Conway, H., Cook, A. J., Corr, H. F. J., Damaske, D., Damm, V., Ferraccioli, F., Forsberg, R., Fujita, S., Gim, Y., Gogineni, P., Griggs, J. A., Hindmarsh, R. C. A., Holmlund, P., Holt, J. W., Jacobel, R. W., Jenkins, A., Jokat, W., Jordan, T., King, E. C., Kohler, J., Krabill, W., Riger-Kusk, M., Langley, K. A., Leitchenkov, G., Leuschen, C., Luyendyk, B. P., Matsuoka, K., Mouginot, J., Nitsche, F. O., Nogi, Y., Nost, O. A., Popov, S. V., Rignot, E., Rippin, D. M., Rivera, A., Roberts, J., Ross, N., Siegert, M. J., Smith, A. M., Steinhage, D., Studinger, M., Sun, B., Tinto, B. K., Welch, B. C., Wilson, D., Young, D. A., Xiangbin, 
375-393, https://doi.org/10.5194/tc-7-375-2013, 2013.

Hills, B. H., Christianson, K., and Holschuh, N.: A framework for attenuation method selection evaluated with icepenetrating radar data at South Pole Lake, Ann. Glaciol., 61(81), 176-187, https://doi.org/10.1017/aog.2020.32, 2020. Howat, I. M., Porter, C., Smith, B. E., Noh, M. J., and Morin, P.: The Reference Elevation Model of Antarctica, The Cryosphere., 13, 665-674, https://doi.org/10.5194/tc-13-665-2019, 2019.

Humbert, A., D. Steinhage, V. Helm, S. Beyer, and T. Kleiner.: Missing Evidence of Widespread Subglacial Lakes at Recovery Glacier, Antarctica, J. Geophys. Res: Earth Surface., 123(11), 2802-2826, https://doi.org/10.1029/2017JF004591, 2018.

IPCC.: IPCC Special Report on the Ocean and Cryosphere in a Changing Climate, https://www.ipcc.ch/srocc/, 2019. Jamieson, S. S. R., Ross, N., Greenbaum, J. S., Young, D. A., Aitken, A. R. A., Roberts, J. L., Blankenship, D. D., Sun, B., Siegert, M. J: An extensive subglacial lake and canyon system in Princess Elizabeth Land, East Antarctica, Geology., 44(2), 87-90, https://doi.org/10.1130/G37220.1, 2016.

Jordan, T. A., Ferraccioli, F., Corr, H., Graham, A., Armadillo, E., and Bozzo, E.: Hypothesis for mega-outburst flooding from a palaeo-subglacial lake beneath the East Antarctic Ice Sheet, Terra Nova., 22(4), 283-289, https://doi.org/10.1111/j.1365-3121.2010.00944.x, 2010.

MacGregor, J. A., Winebrenner, D. P., Conway, H., Matsuoka, K., Mayewski, P. A., and Clow, G. D.: Modeling englacial radar attenuation at Siple Dome, West Antarctica, using ice chemistry and temperature data, J. Geophys. Res: Earth Surface., 112, F03008, https://doi.org/10.1029/2006JF000717, 2007.

Malczyk., G., Gourmelen, N., Goldberg, D., Wuite, J., and Nagler, T.: Repeat Subglacial Lake Drainage and Filling Beneath Thwaites Glacier, Geophys. Res. Lett., 47, e2020GL089658, https://doi.org/10.1029/2020g1089658, 2020.

Mackie, E. J., Schroeder, D. M., Caers, J., Siegfried, M. R., and Scheidt, C.: Antarctic topographic realizations and geostatistical modeling used to map subglacial lakes, J. Geophys. Res: Earth Surface., 125, e2019JF005420. https://doi.org/10.1029/2019JF005420, 2020.

Matsuoka, K., Morse, D., and Raymond, C. F.: Estimating englacial radar attenuation using depth profiles of the returned power, central West Antarctica, J. Geophys. Res: Earth Surface., 115, F02012, https://doi.org/10.1029/2009jf001496, 2010.

Matsuoka, K., MacGregor, J. A., and Pattyn, F.: Predicting radar attenuation within the Antarctic ice sheet, Earth Planet. Sc. Lett., 359-360, 173-183. https://doi.org/10.1016/j.epsl.2012.10.018, 2012.

Morlighem, M., Rignot, E., Binder, T., Blankenship, D., Drews, R., Eagles, G., Eisen, O., Ferraccioli, F., Forsberg, R., Fretwell, P., Goel, V., Greenbaum, J. S., Gudmundsson, H., Guo. J. X, Helm, V., Hofstede, C., Howat, I., Humbert, A., Jokat, W., Karlsson, N. B., Lee, W. S., Matsuoka, K., Millan, R., Mouginot, J., Paden, J., Pattyn, F., Roberts, J., Rosier, S., Ruppel, A., Seroussi, H., Smith, E. C., Steinhage, D., Sun, B., van den Broeke, M. R., van Ommen, T. D., van Wessem, M., and Young, D. A.: Deep glacial troughs and stabilizing ridges unveiled beneath the margins of the Antarctic ice sheet, Nat. Geosci., 13(2), 132-137. https://doi.org/10.1038/s41561-019-0510-8, 2020a.

Napoleoni, F., Jamieson, S. S. R., Ross, N., Bentley, M. J., Rivera, A., Smith, A. M., Siegert, M. J., Paxman, G. J. G., 
the Ellsworth Subglacial Highlands, West Antarctica, The Cryosphere., 14, 4507-4524, https://doi.org/10.5194/tc-144507-2020, 2020.

Ng, G., Lindzey, L. E., Young, D. A., Buhl, D. P., Kempf, S. D., Beem, L.H., Roberts, J. L., Greenbaum, J. S., Blankenship, D. D.: UTIG's Approach to Managing Polar Aerogeophysical Data in the Field: Philosophy and Examples from Fixed Wing and Helicopter Surveys, UTIG Technical Report., University of Texas, Institute for Geophysics:Austin, TX, USA., 2020.

Oswald., G. K. A., and Robin, G. D. E. Q.: Lakes Beneath the Antarctic Ice Sheet, Nature., 245(5423), 251-254, https://doi.org/10.1038/245251a0, 1973.

Parker, R. L.: The Rapid Calculation of Potential Anomalies, Geophysical Journal of the Royal Astronomical Society., 31(4), 447-455, https://doi.org/10.1016/j.epsl.2012.10.018, 1972.

Pattyn, F., Carter, S. P., and Thoma, M.: Advances in modelling subglacial lakes and their interaction with the Antarctic ice sheet, Phil. Trans. R. Soc. A., 374(2059), 20140296, http://dx.doi.org/10.1098/rsta.2014.0296, 2016.

Pattyn, F., et al.: The Greenland and Antarctic ice sheets under $1.5^{\circ} \mathrm{C}$ global warming, Nat. Clim. Change., 8(12), 1053-1061, https://doi.org/10.1038/s41558-018-0305-8, 2018.

Peters, M. E., Blankenship, D. D., Carter, S.P., Kempf, S. D., Young, D. A., and Holt, J, W.: Along-Track Focusing of Airborne Radar Sounding Data From West Antarctica for Improving Basal Reflection Analysis and Layer Detection, IEEE T. Geosci. Remote., 45(9): 2725-2736, https://doi.org/10.1109/tgrs.2007.897416, 2007.

Rignot, E., Mouginot, J., Scheuchl, B., van den Broeke, M., van Wessem, M. J., and Morlighem, M.: Four decades of Antarctic Ice Sheet mass balance from 1979-2017, Proc. Natl. Acad. Sci., 116(4), 1095-1103, https://doi.org/10.1073/pnas.1812883116, 2019.

Rivera, A., Uribe, J., Zamora, R., and Oberreuter, J.: Subglacial Lake CECs: discovery and in situ survey of a privileged research site in West Antarctica, Geophys. Res. Lett., 42, 3944-3953, https://doi.org/10.1002/2015GL063390, 2015.

Siegert, M. J.: A 60-year international history of Antarctic subglacial lake exploration, Geological Society, London, Special Publications., 461, 7-21, https://doi.org/10.1144/SP461.5, 2018.

Siegert, M. J., Ross, N., and Le Brocq, A. M.: Recent advances in understanding Antarctic subglacial lakes and hydrology, .Phil. Trans. R. Soc. A., 374(2059), 20140306, https://doi.org/10.1098/rsta.2014.0306, 2016.

Siegert., M. J., Kwok, R., Mayer, C., and Hubbard, B.: Water exchange between the subglacial Lake Vostok and the overlying ice sheet, Nature., 403(6770), 643-646, https://doi.org/10.1038/35001049, 2000.

Siegfried, M. R., and Fricker, H. A.: Thirteen years of subglacial lake activity in Antarctica from multi-mission satellite altimetry, Ann. Glaciol., 59(76pt1), 42-55, https://doi.org/10.1017/aog.2017.36, 2018.

Smith., W. H. F., and Wesse, P.: Gridding with continuous curvature splines in tension, Geophysics., 55(3), 293-305, https://doi.org/ 10.1190/1.1442837, 1990.

Smoller, Y. L., Yurist, S. S., Golovan, A. A., and Yakushik, L. Y.: Using a multiantenna GPS receiver in the airborne gravimeter GT-2a for surveys in polar areas, Gyroscopy and Navigation., 6(4), 299-304, https://doi.org/10.1134/S2075108715040100, 2015. 
https://doi.org/10.5194/tc-2021-332

Preprint. Discussion started: 3 December 2021

(c) Author(s) 2021. CC BY 4.0 License.

Studinger, M., Bell, R. E., and Tikku, A. A.: Estimating the depth and shape of subglacial lake Vostok's water cavity from aerogravity data, Geophys. Res. Lett., 31(12), L12401, https://doi.org/10.1029/2004GL019801, 2004.

IMBIE.: Mass balance of the Antarctic Ice Sheet from 1992 to 2017, Nature., 558(7709), 219-222, https://doi.org/10.1038/s41586-018-0179-y, 2018.

Wingham, D. J., Siegert, M. J., Shepherd, A., and Muir, A. S.: Rapid discharge connects Antarctic subglacial lakes, Nature., 440(7087), 1033-1036, https://doi.org/10.1038/nature04660, 2006.

Wright, A., and Siegert, M.: A fourth inventory of Antarctic subglacial lakes, Antarctic Science., 24(6), 659-664, https://doi.org/10.1017/S095410201200048X, 2012.

415 Zirizzotti, A., L. Cafarella, J. A. Baskaradas, I. E. Tabacco, S. Urbini, M. Mangialetti, and C. Bianchi.: Dry-Wet Bedrock Interface Detection by Radio Echo Sounding Measurements, IEEE T. Geosci. Remote., 48(5), 2343-2348, https://doi.org/10.1109/tgrs.2009.2038900, 2010. 